\title{
Monetary Policy Transmission under Inflation Targeting in Mongolia
}

\author{
Erdenechuluun Khishigjargal ${ }^{1, *}$ \\ ${ }^{1}$ Dep.of Japanese and Asian Studies, Saitama University, 255, Shimo-Okubo, Sakura-ku, \\ Saitama, 338-8570, Japan \\ *Corresponding author: Tel: 81-48-858-3324. E-mail: hishegee_99@yahoo.com
}

Received: April 4, 2018 Accepted: April 26, 2018 Published: June 10, 2018

doi: 10.5296/rae.v10i2.12950 URL: https://doi.org/10.5296/rae.v10i2.12950

\begin{abstract}
This article aims to examine the monetary policy transmission mechanism under the inflation targeting in Mongolia for the period from June 2007 to August 2017 by applying a recursive vector-autoregressive model. Under the inflation targeting framework, the Bank of Mongolia has established the interest rate corridor since February 2013 for the purpose of improving the interest rate channel of the transmission mechanism. The study then contributes to the literature by assessing whether the interest rate corridor has really improved the policy rate transmission effects by comparing the effects between the pre-corridor period (from June 2007 to February 2013) and the post-corridor period (from March 2013 to August 2017). The main findings of this study are as follows. First, in the post-corridor period the effect of policy rate is clearly transmitted to the lending rate and inflation rate through the responses of interbank market rate, whereas the pre-corridor period does not represent any significant interest rate transmission effects. This outcomes implies that the interest rate corridor has contributed to enhancing monetary policy transmission mechanism. Second, the responses of exchange rate and industrial production to the policy rate shock are not significant even after the adoption of the interest rate corridor. This insignificance might come from the stick policy rate to stabilize the exchange rate, so-called a "fear of floating".
\end{abstract}

Keywords: Bank of Mongolia (BOM), Monetary policy transmission, Inflation targeting, Interest rate corridor, Vector auto regression (VAR), Policy rate

JEL Classification Codes: E52, O53 


\section{Introduction}

The Central Bank of Mongolia (BOM) has adopted one-week central bank bills' rate as a policy rate since July 2007. The background behind introducing the policy rate lies in the fact that the BOM has applied an inflation targeting instead of a monetary aggregate targeting to its monetary policy framework since the same year of 2007: the policy rate is expected to work as an operating target to attain its targeted inflation rate through its transmission mechanism. The BOM, having experienced the challenges of high and volatile inflation, has taken strategic steps to improve the policy rate transmission mechanism to materialize its inflation targeting. The typical example is the establishment of an interest rate corridor in February 2013. This instrument is expected to contribute to improving the interest rate channel of monetary transmission mechanism by reducing volatility in short-term interest rate.

The question then arises on whether the policy rate transmission mechanism in Mongolia has been workable enough to manage its inflation targeting, which has been operated for around one decade since its adoption. In general, there is a vast literature that has studied monetary policy transmission mechanism targeting advanced economies such as the United States and in the euro area economies. Leeper et al. (1998) and Christiano et al. (1999), for instance, reviewed what one has learned from this extensive literature regarding the monetary transmission mechanism in the United States. As far as developing economies such as Mongolia are concerned, however, there has been rather less evidence on the transmission mechanism due to the relatively shorter history of their policy rate operations and due to their operational difficulties.

This article aims to examine the monetary policy transmission mechanism under the inflation targeting in Mongolia for the period from June 2007 to August 2017. To be specific, the sample period is divided into the period before the establishment of interest rate corridor from June 2007 to February 2013 (the pre-corridor period) and the period after it from March 2013 to August 2017 (the post-corridor period). The study then estimates the impulse responses of transmission variables including inflation rate to the structural policy rate shock by applying the structural vector-autoregressive (SVAR) through imposing the Cholesky restriction on the model specification for both the pre-corridor and the post-corridor periods, and verifies whether the policy rate transmission mechanism has been really improved to control inflation rate after establishing the interest rate corridor by comparing the estimations for both periods.

The paper is structured as follows. Section 2 gives an overview of the monetary policy framework in Mongolia; Section 3 reviews the literature on the monetary policy transmission mechanism and clarified this study's contribution; Section 4 conducts the empirical analyses by showing the data and methodology for a SVAR estimation and the estimation results with their interpretations; and Section 5 summarizes and concludes. 


\section{Overview on Monetary Policy Framework in Mongolia}

This section first describes the short history of the monetary policy framework since the 1990s in Mongolia, observes the performance in Mongolian inflation targeting in connection with the policy rate stances since its adoption in 2007, and illustrates the monetary policy transmission mechanism in Mongolia. ${ }^{1}$

\subsection{Development of Monetary Policy Framework since the 1990s}

The Mongolian economic system shifted from a centrally planned economy to a market-based economy in early 1990s, and a great number of political and economic reforms have been undertaken since then. In 1991, Mongolia approved a new banking law and organized the two-tier banking system: the BOM implements monetary policy as a central bank, and other banks yields commercial services. Regarding the monetary policy framework, it has the following three phases since the 1990s: monetary aggregate targeting from 1995 to 2006, transition to inflation targeting from 2007 to 2011, and inflation targeting with forward-looking framework from 2011 to the present.

In the first phase of monetary aggregate targeting for 1995-2006, the BOM set the reserve money as the operating target and M2 as the intermediate target, only through the policy instruments of operating central bank bill and reserve requirement. Since the mid-2000s, however, the relationship between reserve money and broad money, namely, the money multiplier, became unstable and the impact of money supply on inflation became ambiguous due to financial deepening, fiscal dominance and its monetization process. Hence came the necessity for the BOM to apply alternative monetary policy framework.

In the second phase from 2007, the BOM initiated inflation targeting, which contains the policy mandate of announcing the mid-term targeted inflation rate to the public and of taking every possible measures to maintain inflation rate within its targeted range. At the same time, the BOM has adopted one-week central bank bills' rate as a policy rate since July 2007, so that the policy rate can work as an operating target to attain its targeted inflation rate through its transmission mechanism. Mongolian economy was, however, hit by the wave of world financial crisis in 2009, and the BOM adopted the IMF Stand-by program in that year in order to safeguard the foreign exchange reserves and relieve immediate pressure on exchange rate. The program's terms required BOM to target monetary aggregate by putting ceiling on net domestic assets and setting a floor for net foreign assets. In 2010, the BOM finally completed 18 months Stand-by program.

In the third phase from 2011, the BOM has been developing the Forecasting and Policy Analysis System (FPAS), for the purpose of upgrading the inflation targeting to a forward-looking framework. The system aims at forecast-based policy formation and decision making, and effective communication with the public under the inflation targeting framework. In this phase, the BOM also have improved its operational framework by establishing an interest rate corridor since February 2013. The interest rate corridor around the policy rate consists of two standing facilities: the rate of overnight repo facility as the ceiling (policy rate plus two percent points) and the rate of overnight deposit facility as the 


\section{Macrothink Institute ${ }^{T M}$}

floor (policy rate minus two percent points). Setting the corridor is expected to contribute to improving interest rate channel of monetary transmission mechanism.

\subsection{Performance of Inflation Targeting}

This section, focusing on the second and third phases above after 2007, observes the performance of the inflation targeting by comparing the targeted inflation with the actual inflation and by associating the trend in inflation with the policy rate stances.

Figure 1 compares the actual inflation rate with the targeted rate in terms of annual rate at each year-end, in which the targeted inflation rate is updated by the BOM's Monetary Policy Guidelines for each year. Figure 2 illustrates the central bank's policy rate and the interest rate corridor in comparison with the interbank market rate.

Soon after the adoption of the inflation targeting in 2007, Mongolian economy was hit by the wave of world financial crisis in 2009, and the BOM adopted the IMF Stand-by program in that year. At that time, the main focus of the BOM was to restore the confidence in the local currency and to stop the deposit flight out of its economy, and the BOM thus raised its policy rate from 9.75 percent to 14 percent in March 2009, although the BOM afterwards reduced its policy rate gradually to 10 percent in September in accordance with the declining inflation rate.

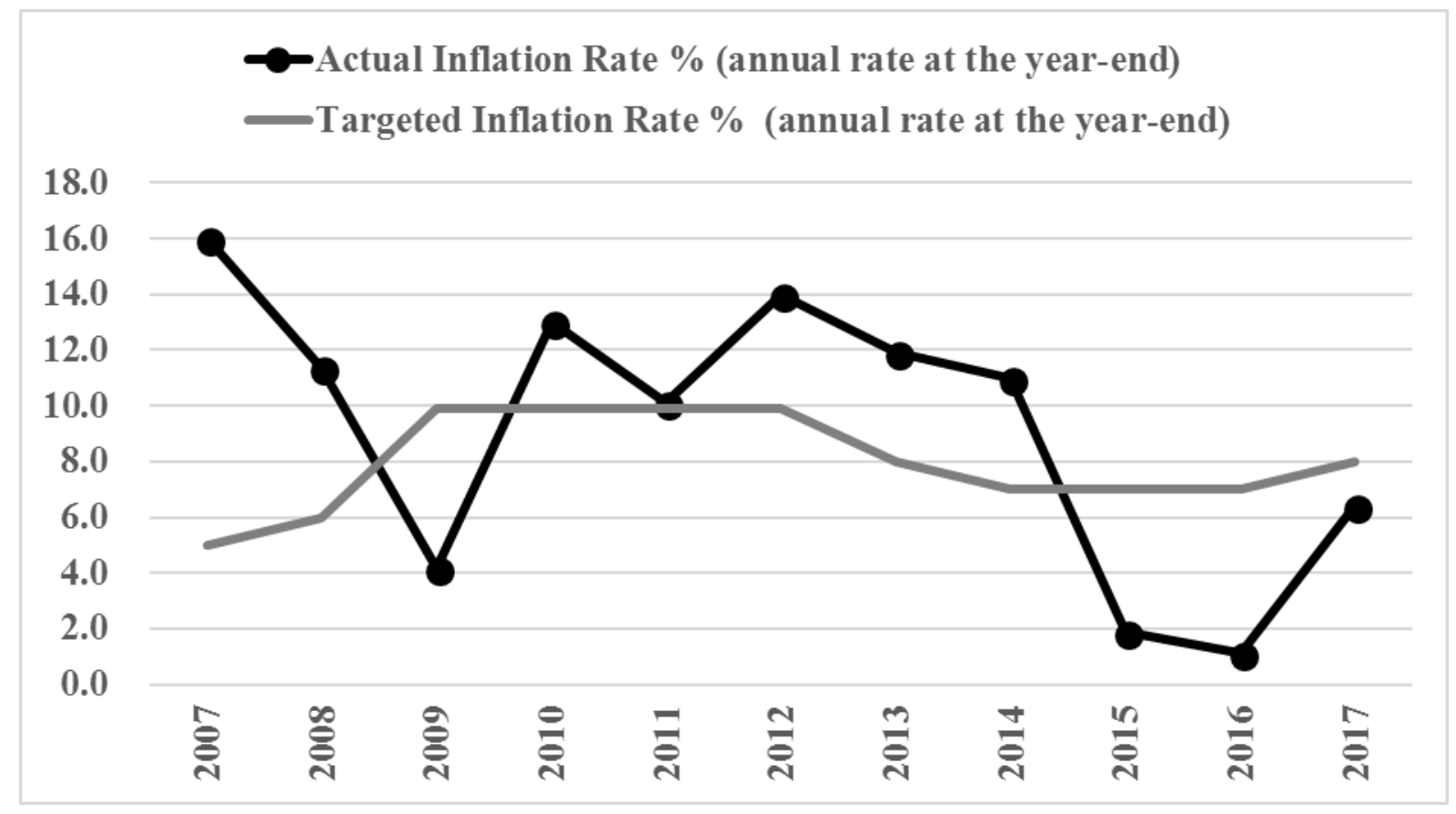

Source: Author's description based on the website of the Bank of Mongolia

Figure 1. Actual Inflation and Targeted Inflation 


\section{Macrothink}

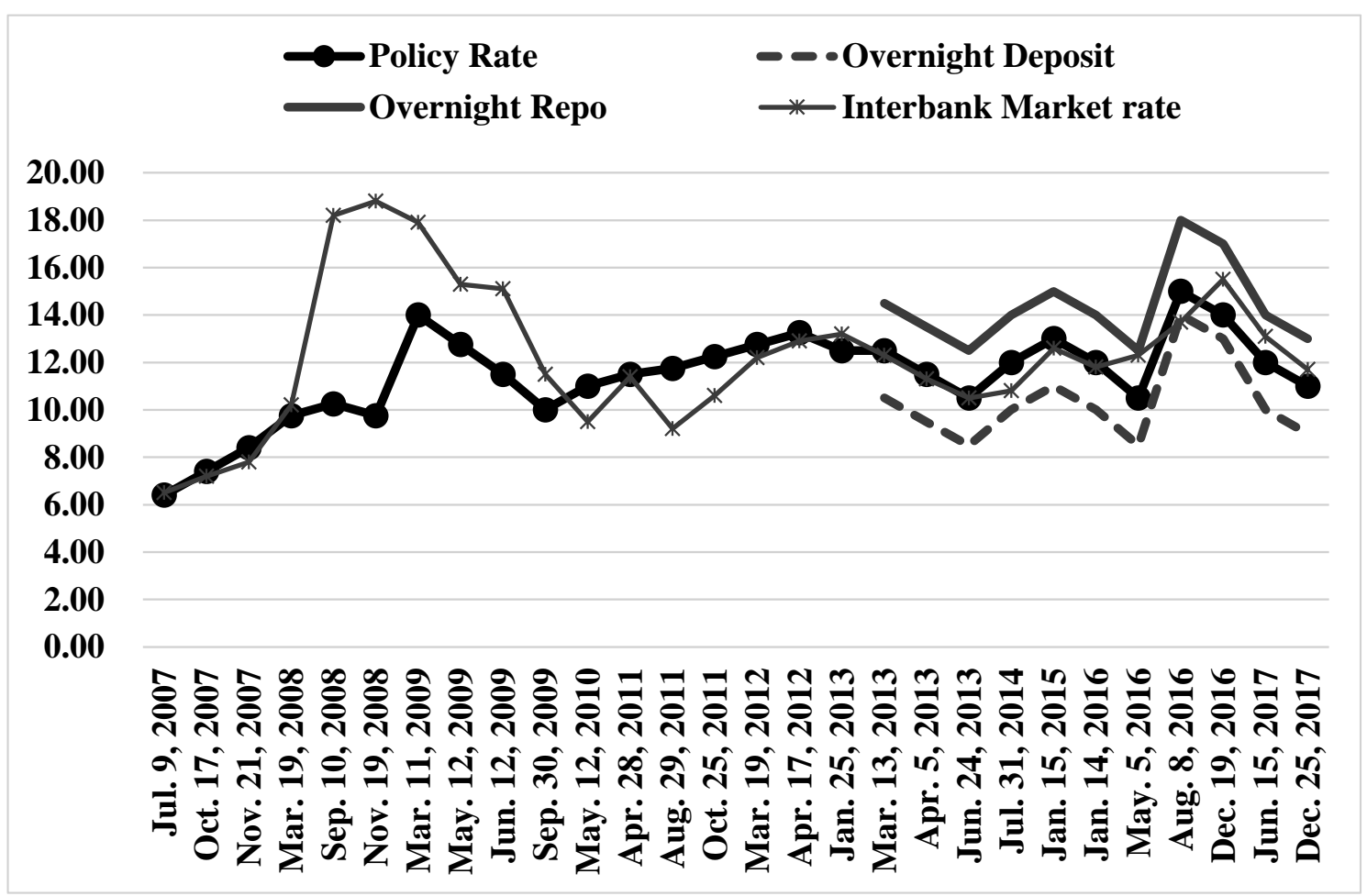

Source: Author's description based on the website of the Bank of Mongolia

Figure 2. Policy Rate, Corridor Rates and Interbank Market Rate

For the period from 2010 to 2013, Mongolian economy entered the booming stage with double-digit inflation rate, which was mostly beyond the targeted rate that pursued a single-digit level. There were the following reasons behind the fueling inflation: the price elevation of food (e.g. meat, wheat), fuel (e.g. gasoline) and public administrative goods in the supply side, the expansionary fiscal policy particularly in terms of the cash handout to the public from the specific government fund and the sore of capital inflows in the mining sector in the demand side. The BOM reacted the hike of inflation by raising its policy rate continuously to 13.25 percent until January 2013. At the same time, the BOM together with the Government initiated the "Medium-term Price Stabilization Program" containing the programs to stabilize food and fuel prices in October 2012 to decrease the supply side pressure on inflation. As a result of these policies, the inflationary pressure was calming down to some degree, thereby the BOM cutting again its policy rate consecutively from January to June in 2013 toward 10.5 percent. The interest rate corridor was also initiated from February 2013 as was stated before. As Figure 2 showed clearly, before the corridor adoption there was large deviations between the policy rate and the interbank market rate, but after its adoption, those deviations have been settled down within the corridor range.

For 2014-2015, under the background of the slowdown in the world economy including Chinese economy, the net inward foreign direct investment to Mongolia fell down significantly (in 2014 by 17 times less than its peak in 2011), thereby the balance of payment facing difficulties. To improve external balance, the BOM turned to tight monetary policy by raising its policy rate to 12 percent in July 2014 and further to 13 percent in January 2015. At 
the end of 2015, the inflation rate fell down to 1.9 percent as year-on-year rate, which was far below the targeted rate.

After 2016, the BOM eased its monetary policy by cutting its policy rate to 12 percent in January 2016 and further to 10.5 in May 2016, considering that the inflation rate remained below the targeted rate. The BOM, however, raised its policy rate again to 15 percent in August 2016, since during July to August the shortage of foreign reserves incurred the rapid currency depreciation, which endangered the capital flight. After avoiding a currency crisis, the BOM started to reduce its policy rate gradually and continuously from December 2016 through 2017. The inflation rates in 2016 and 2017 were still below the targeted rate at the year-end.

To sum up, in the early stage of inflation targeting for 2007-2013, the actual inflation rate tended to exceed the targeted rate in spite of tight monetary policies due to fiscal and supply-side pressures. In the latter stage for 2015-2017, on the contrary, the inflation rate has been will-restrained under the targeted rate. The critical issue is that even under such a stagnant economic condition for that period, the BOM has still kept its policy rate at rather high level, namely, more than ten percent. As the aforementioned story told us, the constraint in the BOM monetary policy comes from the difficulty in balance of payment caused mainly by the sharp decline in inward foreign direct investment and at the same time the difficulty in the fluctuation of local currency value, so-called, "fear of floating", which will be explained in the next section.

\subsection{Monetary Policy Transmission Mechanism}

The BOM supposes four kinds of channels of the policy rate transmission mechanism: the channels through interest rate, exchange rate, asset prices and inflation expectation. ${ }^{2}$ The last two channels are not considered to be major transmissions, following the argument of Bayardavaa et al. (2015). The channel of asset prices depends on the development of stock market, but as a matter of fact the banking sector comprises over 95 percent of the financial sector in Mongolian economy. The channel of inflation expectation cannot also be expected due to the lack of monetary policy credibility coming from the history of high and volatile inflation. The study focuses on the channels of interest rate and exchange rate.

Regarding the interest rate channel, the effect of the policy rate shock is expected to be transmitted to the interbank market rate, to deposit and lending rate, and finally to inflation and output, consecutively. In this channel, Bayardavaa et al. (2015) points out the following drawbacks. First, the policy rate shock has not necessarily been transmitted to the interbank market rate in a parallel way in Mongolia as Figure 2 showed in the previous section. It is due to the underdevelopment of interbank market: the size of interbank market are marginal and most of the transactions there are settled among only five or six banks. This market structure allowed the deviation between the policy rate and the interbank market rate. After the adoption of the interest rate corridor, however, their transmission has been improved as was also indicated in Figure 2. Second, the transmission from the policy rate to the deposit and lending rate also has not always worked well due to the structure of banking sector: the fierce competition among three major banks makes it difficult to decrease their deposit rates or 
increase their lending rates in the fear of losing their depositors and customers. Third, the subsidized loans from the BOM have blurred the policy rate transmission effect, since most of the direct financing were charged at fixed preferential rate under the contract period. The aforementioned "Medium-term Price Stabilization Program" in October 2012 contained this direct lending programs in such prioritized sectors as construction and housing.

As for the exchange rate channel, the effect of the policy rate chock is expected to be transmitted to the exchange rate, and to inflation and output through the pass-through effect of import and export prices. Bayardavaa et al. (2015) argued that the effectiveness of this channel depends on the central bank's willingness to allow the fluctuation of exchange rate. In general, developing countries usually faces the problem of a "fear of floating", as suggested by Calvo and Reinhart (2002). It comes from a lack of confidence in currency value, especially given that their external debts are primarily denominated in US dollars. Mongolian economy is not an exception, since the BOM has still kept its policy rate at more than ten percent in 2015-2016 even under the inflation rate below the target, only for the purpose of preventing Mongolian currency value from depreciating rapidly. It might lose the sensitivity of exchange rate to the policy rate shock, thereby lessening the effectiveness of the exchange rate channel.

To sum up, the interest rate channel is expected to play a major role in the policy rate transmission mechanism, in particular, after the adoption of the interest rate corridor in February 2013. As for the exchange rate channel, on the other hand, the problem of a "fear of floating" might mitigate the effect of the policy rate transmission.

\section{Literature Review and Contribution}

This section reviews previous studies on the monetary policy transmission mechanism and clarifies this paper's contribution. There is a vast literature that has studied the transmission mechanism targeting advanced economies such as the United States and in the euro area economies. Leeper et al. (1998) and Christiano et al. (1999), for instance, reviewed what one has learned from this extensive literature regarding the monetary transmission mechanism in the United States.

As far as developing economies such as Mongolia are concerned, however, there has been rather less evidence on the transmission mechanism due to the relatively shorter history of their policy rate operations and also due to their operational difficulties such as weak institutional capability and underdevelopment of financial market. For the studies on Central Asia, Isakova (2008) investigated the monetary transmission mechanism in Kazakhstan, the Kyrgyz Republic and Tajikistan, by using a vector-autoregressive (VAR) model. The study argued that the transmission of exchange rate pass-through on prices is the strongest channel due to the high degree of dollarization, whereas the interest rate channel to prices and output is limited due to weak financial intermediation, and suggested policy implications such as the needs to deepen local financial sectors and to develop financial intermediation. For Southeast Asia, Taguchi and Kato (2011), focusing on Indonesia, Korea, the Philippines and Thailand, 
examined the effects of their monetary policy shocks on prices (together with their monetary policy rules) by using a VAR model. They found that Korea took an inflation-responsive and forward-looking policy rule, in which the price response to a policy shock was confirmed, while Indonesia and Thailand conducted backward-looking rules, where the price responses were not identified.

Regarding the Mongolian case, there were several studies published in the series of the BOM research books, but most of them targeted the period before the adoption of policy rate in 2007. Luvsannyam (2004) and Doojav and Borkhuu (2004), for instance, examined the monetary transmission mechanism for the period under the monetary aggregate targeting framework by using a VAR model, and emphasized the exchange rate channel as the most significant one in the transmission mechanism. The recent study covering the period after the adoption of the policy rate is represented by Bayardavaa et al. (2015). This study explored a comprehensive picture of the transmission channels of monetary policy shock to inflation and output for 2002-2015 by adopting a VAR model. Their main findings were as follows: lending rate responded to unexpected monetary policy shock in the first and second quarter after the shock; the response of exchange rate was within the quarter of the shock but it was only significant as ten percent; lending rate and bank credit to private sector could affect both inflation and output with a delay of three and five quarters, respectively. Based on the findings, the study finally suggested that monetary policy should focus on the bank lending channel as transmission mechanism in Mongolian economy.

This study contributes to the reviewed literature above on the assessment of Mongolian monetary policy transmission mechanism as follows. First, this study updates its assessment by extending the sample period from July 2007 to August 2017, and thus makes it possible to review fully and exclusively the transmission mechanism under the adoption of the inflation targeting and the policy rate. Second, this study evaluates the interest rate corridor adopted since February 2013, a critical reformation of the policy rate transmission. Extending the sample period to August 2017 allows the total sample to be divided into the pre-corridor period and the post-corridor period. Comparing the responses of transmission variables to the policy rate shock between the pre-corridor and the post-corridor period makes it possible to assess whether the interest rate corridor has really improved the policy rate transmission effects. Any of studies in the aforementioned literature did not cover this critical period for assessing the interest rate corridor.

\section{Empirics}

This section conducts the empirical analyses of examining the monetary transmission effects by comparing the effects in the pre-corridor period and those in the post-corridor period in Mongolia. The section clarifies theoretical assumptions, data for key variables, methodology for a SVAR model estimation, and outcomes with their interpretations.

\subsection{Theoretical Assumptions and Key Variables for Estimation}

Before conducting model estimations, theoretical assumptions should be clarified as follows. 


\section{Mll Macrothink}

The most important assumption is about the nature of the interaction of the monetary policy shock with the other transmission variables. This study assumes that monetary policy would be exogenous and ordered at the beginning of the recursive VAR model. This assumption is consistent with the argument of Christiano et al. (1999) that monetary policy shocks are orthogonal to the other variables. As the policy variable, this study adopts the central bank policy rate (denoted by por) that the BOM has introduced since July 2007 together with the inflation targeting.

Regarding the other transmission variables, the study focuses on the interest rate channel and the exchange rate one, by considering the current transmission mechanism in Mongolia as described in Section 2.3. Under the constraint of limited time-series samples, the study confines estimated variables to the following five key variables for the estimation: interbank market rate (itr); long-term lending rate in terms of weighted average (ldr); exchange rate in terms of national currency per US Dollar in period average, which is expressed as its year-on-year change rate (exr); consumer price index, which is also transformed into its year-on-year change rate (cpi); and total industrial production, which is processed into its year-on-year change rate (ind). Although money supplies are often used for the transmission analyses, this study excludes them, since the impact of money supply on inflation has become ambiguous in Mongolia as described in Section 2.1.

This study then assumes the recursive order in the model estimation as follows: policy rate (por), interbank market rate (itr), lending rate (ldr), exchange rate (exr), inflation rate (cpi) and industrial production (ind). The order is based on the assumption that monetary policy reactions are transmitted first to money markets represented by interbank market rate, lending rate and exchange rate, and later to real markets shown by inflation rate and industrial production.

As for the data sources for the variables, the data of policy rate, interbank rate, long term lending rate and exchange rate are retrieved from the BOM database, while those of consumer prices and industrial production are from the database of the National Statistical Office (NSO). All the sample data for the estimation are monthly one from June 2007 to August 2017. Figure 3 simply displays the overview of key six variables.

From the simple observation in Figure 3, there appear to be some positive correlations among central bank policy rate, interbank market rate and long-term lending rate, and some negative ones between consumer price index and those interest rate variables. On the other hand, there seems to be no clear relationship among exchange rate, total industrial production and interest rate variables. To explore a monetary policy transmission, therefore, the variable interactions should be put in a statistical test by applying a breakpoint test between the pre-corridor period and the post-corridor one and by using a SVAR model in the next section. 


\section{MInstitute Macrothink $_{\text {Instite }}$}
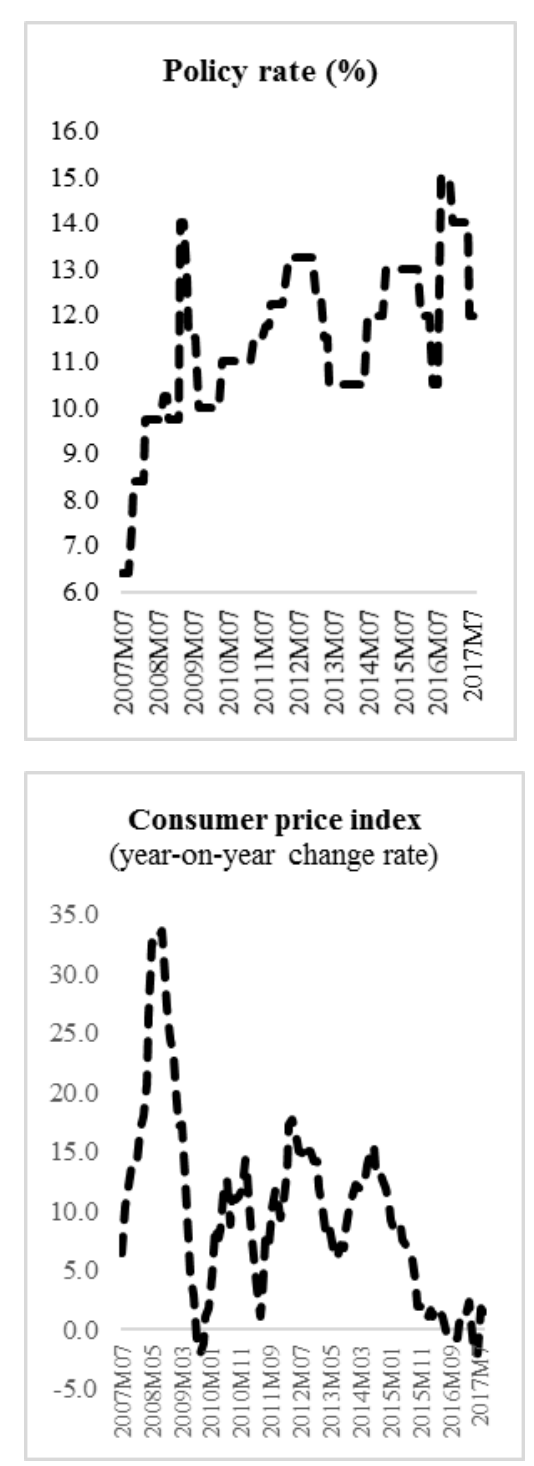

\section{Interbank market rate}

(\%)
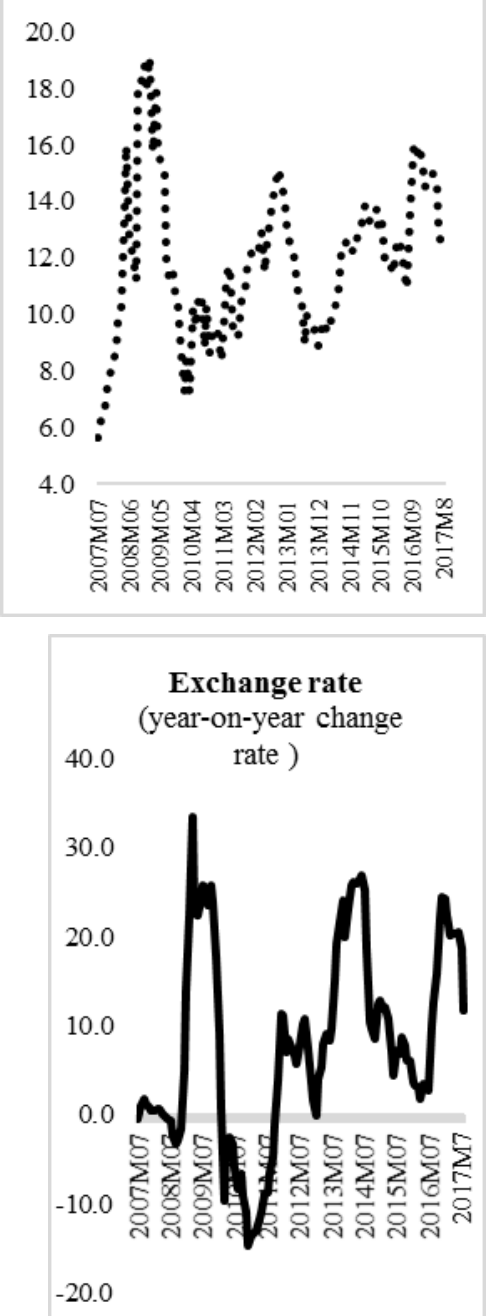

Weighted average lending rate $(\%)$

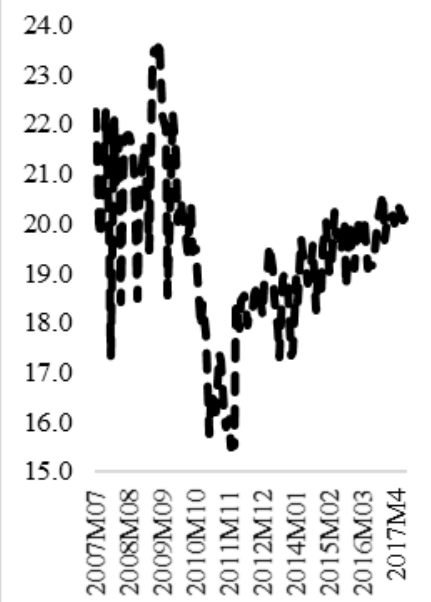

Total industrial production (year-on-year change)

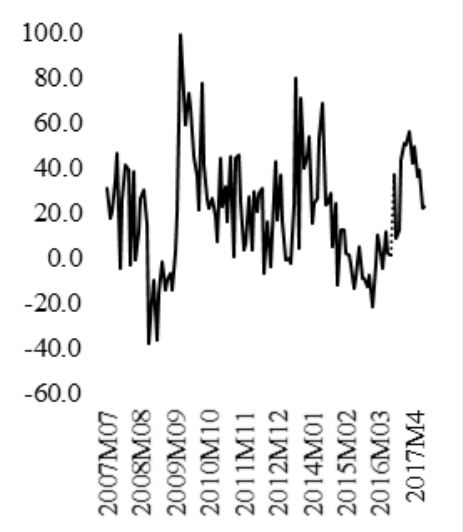

Sources: The database of Bank of Mongolia (BOM), National Statistical Office of Mongolia (NSO)

Figure 3. Data of Key Variables

Before conducting the estimations below, the study investigates the stationary property of the data for each variable, by employing the augmented Dickey-Fuller (ADF) test on the null hypothesis that each variable has a unit root in the test equation including "intercept" (see Said \& Dickey, 1984). Table 1 reports the test results for the data for all the variables, i.e., policy rate (por), interbank market rate (itr), lending rate $(l d r)$, exchange rate (exr), inflation rate (cpi), industrial production (ind). The test rejected a unit root in all the data at the conventional level of significance by more than 90 percent, thereby their data showing stationary property. Thus their data are justified to be used for the subsequent estimations. 
Table 1. ADF Unit Root Test

\begin{tabular}{ccc}
\hline & t-Statistic & Probability \\
\hline por & $-3.331 * *$ & 0.015 \\
$i t r$ & $-3.206 * *$ & 0.022 \\
$l d r$ & $-4.318 * * *$ & 0.000 \\
exr & $-2.691 *$ & 0.078 \\
$c p i$ & $-2.792 *$ & 0.062 \\
ind & $-5.988 * * *$ & 0.000 \\
\hline
\end{tabular}

Source: Author's estimation based on the database of BOM and NSO

Note: $* * *, * * *$ denote rejection of null hypothesis at the $99 \%, 95 \%$ and $90 \%$ level of significance, respectively.

\subsection{Methodology for a SVAR Model Estimation}

This section conducts a SVAR model estimation to examine the transmission mechanism of monetary policy shocks in the pre-corridor period and in the post-corridor period in Mongolia. The reason why the analysis applies a SVAR model is based on the assumption that the concerned variables should be contemporaneously and dynamically interdependent. In this context, identifying and extracting a pure policy shock requires imposing some restrictions on the model system based on theoretical grounds. As a matter of fact, a SVAR model originated from monetary policy analysis where it has been used extensively to study the transmission of monetary policy shocks, which was pioneered by e.g., Bernanke (1986) and Bernanke and Blinder (1992).

The study starts to specify a reduced-form equation for the VAR estimation in the following way.

$$
y_{t}=\mu+V y_{t-1}+e_{t}
$$

where $y_{t}$ is a column vector of the endogenous variables with year $t$, i.e., $y_{t}=\left(\text { por }_{t} i t r_{t} l d r_{t} \text { exr }_{t} \text { cpi }_{t}{ }_{\text {ind }}\right)^{\prime}$ for examining monetary policy transmission effects, $\mu$ is a constant vector; $V$ is a coefficient matrix; $y_{t-1}$ is a vector of the lagged endogenous variables; and $e_{t}$ is a vector of the random error terms in the system. Regarding the lag interval, the lag length (-1) is selected based on Schwarz information criterion with maximum lag being equal to (-2) under the limited number of observations on the divided samples from June 2007 to August 2017.

The total sample is divided into two periods: the one from June 2007 to February 2013 and the other from March 2013 to August 2017, based on the fact that the BOM has adopted an interest rate corridor to enhance monetary policy transmission mechanism since February 2013 as stated in the previous section. The existence of a structural change in the transmission mechanism in February 2013 could be statistically verified by Chow's breakpoint test to diagnose a breakpoint by the F-statistics with probabilities for the 
hypothesis of parameter stability over different periods for the bilateral combinations of concerned variables, i.e., central bank policy rate and the other five variables. Table 2 identified the existence of a breakpoint in February 2013 in all the combinations except the one with industrial production. The analysis thus conducts a model estimation of (1) for the different periods for June 2007 - February 2013 and for March 2013 - August 2017.

Table 2. Chow Breakpoint Test in February 2013

\begin{tabular}{lcc}
\hline & F-Statistic & Probability \\
\hline por \& itr & $2.447 *$ & 0.090 \\
por \& $l d r$ & $10.830^{* * *}$ & 0.000 \\
por \& exr & $12.074 * * *$ & 0.000 \\
por \& cpi & $11.031^{* * *}$ & 0.000 \\
por \& ind & 0.005 & 0.994 \\
\hline
\end{tabular}

Source: Author's estimation based on the database of BOM and NSO

Note: $* * *, *$ denote rejection of null hypothesis at the $99 \%$ and $90 \%$ level of significance, respectively.

Based on the reduced-form VAR model estimation (1), the study examines the impulse responses of five concerned variables to the shock of central bank policy rate to elucidate its transmission mechanism. In examining the impulse response, the structural policy shock should be identified by imposing some restrictions in the SVAR model specification. In general, to identify structural shocks, there are several approaches to impose the restrictions: short-run restrictions and long-run restrictions. This study, based on the theoretical assumptions described in Section 4.1, employs the Cholesky restriction as one of the short-run restrictions, with the following recursive order: policy rate (por), interbank market rate (itr), lending rate $(l d r)$, exchange rate (exr), inflation rate (cpi) and industrial production (ind). Under the Cholesky restriction, the error term of reduced-form equation (1) is linked with that of the SVAR model so that the structural policy shock can be identified.

The expected impulse responses of transmission variables to the policy rate shock are as follows: positive responses of interbank market rate (itr) and lending rate (ldr), and negative responses of exchange rate (exr), inflation rate (cpi) and industrial production (ind).

\subsection{Estimation Outcomes and Their Interpretations}

Table 3 and Figure 4 report the estimation outcomes of the impulse responses of transmission variables to the structural shock of central bank policy rate with 95 percent significant level over eight-month horizon, for the pre-corridor period of June 2007 - February 2013 in Table 3.1 and Figure 4.1, and for the post-corridor period of March 2013 - August 2017 in Table 3.2 and Figure 4.2.

Regarding the impulse responses for the pre-corridor period in Table 3.1, it is only interbank market rate (itr) that shows the expected responses: the interbank market rate responds positively to the policy rate shock at 95 percent significant level in $2^{\text {nd }}$ to $3^{\text {rd }}$ month after the 
shock. The lending rate $(l d r)$ and the exchange rate (exr) shows even the opposite responses from our expectation, while the inflation rate (cpi) and the industrial production (ind) represent no significant responses.

As for the impulse responses for the post-corridor period in Table 3.2, three transmission variables of interbank market rate, lending rate and inflation rate clearly indicate the expected responses: the interbank market rate and the lending rate respond positively to the policy rate shock at significant level in $1^{\text {st }}$ (or $2^{\text {nd }}$ ) to $7^{\text {th }}$ month after the shock; the inflation rate responds negatively to the shock in $3^{\text {rd }}$ to $8^{\text {th }}$ month after the shock. The exchange rate and the industrial production, on the other hand, reveal no significant responses.

The estimation outcomes above could be interpreted as follows. First, there is a clear contrast in the responses of the transmission variables of lending rate and inflation rate between the pre-corridor period and the post-corridor one as shown in Figure 4.1 and 4.2. The post-corridor estimation demonstrates that the effect of policy rate is clearly transmitted to the lending rate and inflation rate through the longer responses of interbank market rate, whereas the pre-corridor one does not represent any significant transmission effects to their variables. This outcomes implies that the framework of the interest rate corridor the BOM has adopted since February 2013 has contributed successfully to enhancing monetary policy transmission mechanism, in particular, in controlling inflation rate. This is rather a new finding after the adoption of the interest rate corridor, which has not been studied previously in the existing literature.

Second, it should be noted that the responses of exchange rate and industrial production to the policy rate shock are still not significant even after the adoption of the interest rate corridor. This result is rather different from the outcomes of previous studies: Luvsannyam (2004) and Doojav and Borkhuu (2004) emphasized the exchange rate channel in the monetary policy transmission mechanism, and Bayardavaa et al. (2015) identified the effect of monetary policy on both inflation and output. The background of the insignificance of exchange rate and industrial production seems to lies in the fact that the BOM has still kept its policy rate at rather high level, more than ten percent, even after the inflation rate was slowing down to around two percent in 2015 and 2016, with the intention to prevent Mongolian currency value from depreciating rapidly. The policy rate sticky to its double-digit rate to stabilize the exchange rate even after 2015, so-called a "fear of floating", might lose the sensitivity of exchange rate and output in the Mongolian economy.

\section{Concluding Remarks}

This article examined the monetary policy transmission mechanism under the inflation targeting in Mongolia for the period from June 2007 to August 2017 by applying a recursive vector-autoregressive model. Under the inflation targeting framework, the BOM has introduced the policy rate since July 2007, and has established the interest rate corridor since February 2013, for the purpose of improving the interest rate channel of the transmission mechanism. The study then contributed to the literature by assessing whether the interest rate 
corridor has really improved the policy rate transmission effects by comparing the effects between the pre-corridor and the post-corridor period.

The main findings of this study are as follows. First, there is a clear contrast in the responses of the lending rate and inflation rate to the policy rate shock between the pre-corridor period and the post-corridor one: in the post-corridor period the effect of policy rate is clearly transmitted to the lending rate and inflation rate through the longer responses of interbank market rate, whereas the pre-corridor period does not represent any significant interest rate transmission effects. This outcomes implies that the framework of the interest rate corridor has contributed successfully to enhancing monetary policy transmission mechanism, in particular, in controlling inflation rate. Second, the responses of exchange rate and industrial production to the policy rate shock are not significant even after the adoption of the interest rate corridor. This insignificance might come from the stick policy rate to stabilize the exchange rate, so-called a "fear of floating".

Table 3. Impulse Responses to Policy Rate Shock for Pre-corridor Period

\begin{tabular}{clllll}
\hline & itr & $L d r$ & Exr & $C p i$ & Ind \\
\hline \multirow{2}{*}{ M1 } & 0.264 & -0.262 & $0.930 * *$ & 0.298 & 1.816 \\
& $(0.171)$ & $(0.156)$ & $(0.384)$ & $(0.274)$ & $(2.587)$ \\
M2 & $0.297 * *$ & -0.190 & 0.311 & 0.107 & 0.358 \\
& $(0.141)$ & $(0.113)$ & $(0.490)$ & $(0.315)$ & $(1.536)$ \\
M3 & $0.305 * *$ & -0.189 & -0.043 & -0.132 & -0.405 \\
& $(0.146)$ & $(0.110)$ & $(0.596)$ & $(0.373)$ & $(1.460)$ \\
M4 & 0.280 & -0.208 & -0.199 & -0.379 & -0.798 \\
& $(0.153)$ & $(0.111)$ & $(0.684)$ & $(0.426)$ & $(1.365)$ \\
M5 & 0.229 & $-0.226 * *$ & -0.224 & -0.608 & -0.905 \\
& $(0.159)$ & $(0.112)$ & $(0.751)$ & $(0.471)$ & $(1.274)$ \\
M6 & 0.162 & $-0.235 * *$ & -0.179 & -0.804 & -0.793 \\
& $(0.164)$ & $(0.114)$ & $(0.798)$ & $(0.506)$ & $(1.203)$ \\
M7 & 0.088 & $-0.236 * *$ & -0.113 & -0.960 & -0.533 \\
& $(0.167)$ & $(0.116)$ & $(0.826)$ & $(0.533)$ & $(1.152)$ \\
M8 & 0.014 & -0.230 & -0.057 & -1.075 & -0.192 \\
& $(0.171)$ & $(0.119)$ & $(0.838)$ & $(0.553)$ & $(1.119)$ \\
\hline
\end{tabular}

Source: Author's estimation based on the database of BOM and NSO

Note: ** denotes rejection of null hypothesis at the $95 \%$ level of significance. The numbers in parentheses are for standard errors. 

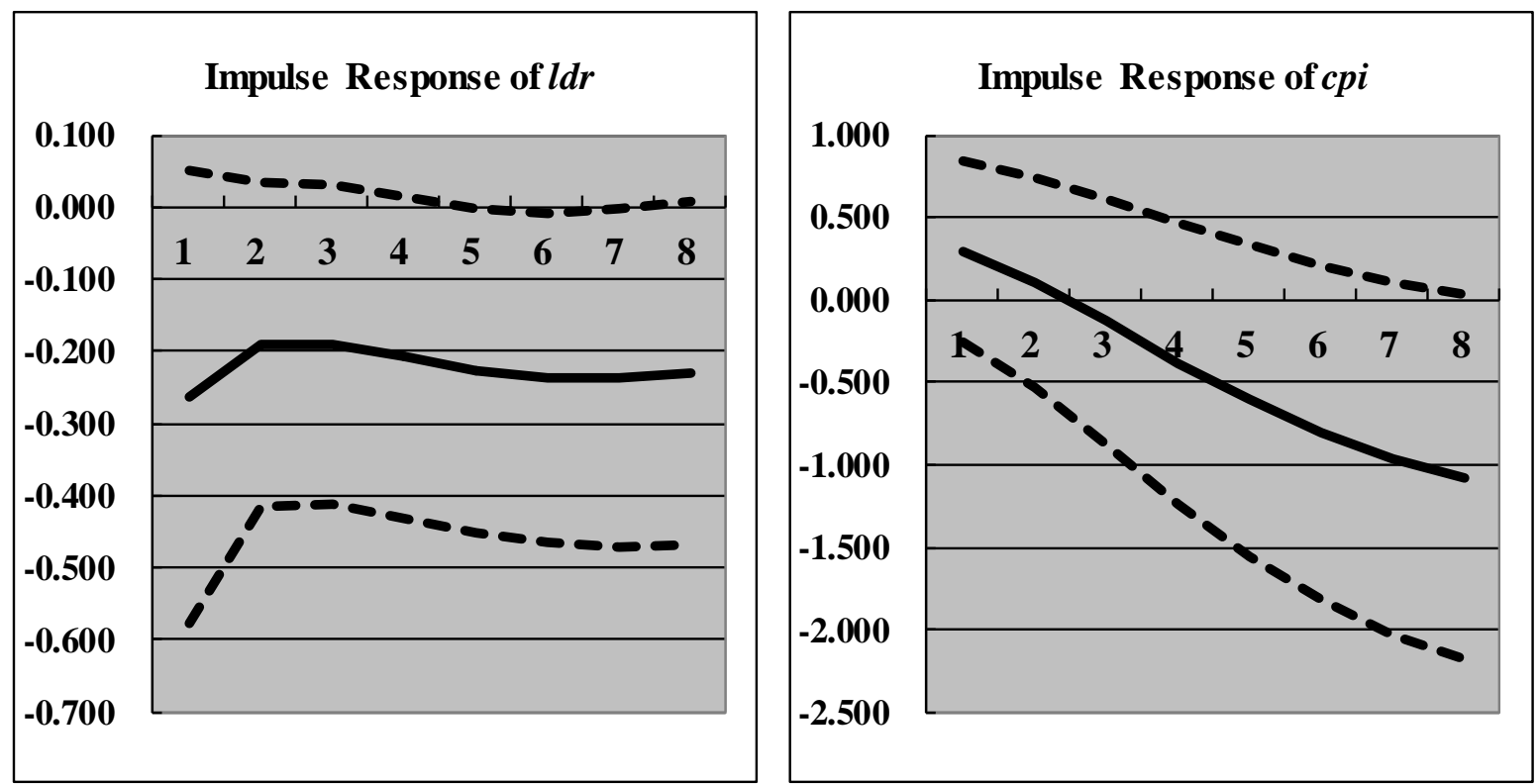

Source: Author's estimation based on the database of BOM and NSO

Figure 4.1. Impulse Responses of $i d r$ and $c p i$ for Pre-corridor Period

Table 3.2. Impulse Responses to Policy Rate Shock for Post-corridor Period

\begin{tabular}{clllll}
\hline & \multicolumn{1}{c}{ itr } & \multicolumn{1}{c}{ ldr } & \multicolumn{1}{c}{ exr } & ind \\
\hline \multirow{2}{*}{ M1 } & $0.555 * *$ & 0.142 & 0.655 & -0.149 & 0.820 \\
& $(0.086)$ & $(0.079)$ & $(0.384)$ & $(0.134)$ & $(2.445)$ \\
M2 & $0.755 * *$ & $0.188 * *$ & 0.613 & -0.274 & -2.981 \\
& $(0.121)$ & $(0.074)$ & $(0.505)$ & $(0.173)$ & $(2.320)$ \\
M3 & $0.712 * *$ & $0.191 * *$ & 0.298 & $-0.448 * *$ & -1.282 \\
& $(0.150)$ & $(0.062)$ & $(0.587)$ & $(0.205)$ & $(1.895)$ \\
M4 & $0.655 * *$ & $0.174 * *$ & 0.073 & $-0.576 * *$ & -1.091 \\
& $(0.172)$ & $(0.061)$ & $(0.655)$ & $(0.242)$ & $(1.906)$ \\
M5 & $0.588 * *$ & $0.158 * *$ & -0.091 & $-0.682 * *$ & -0.935 \\
& $(0.189)$ & $(0.062)$ & $(0.710)$ & $(0.281)$ & $(1.955)$ \\
M6 & $0.525 * *$ & $0.144 * *$ & -0.201 & $-0.767 * *$ & -0.830 \\
& $(0.202)$ & $(0.062)$ & $(0.752)$ & $(0.321)$ & $(1.981)$ \\
M7 & $0.468 * *$ & $0.132 * *$ & -0.265 & $-0.831 * *$ & -0.703 \\
& $(0.210)$ & $(0.063)$ & $(0.781)$ & $(0.360)$ & $(1.983)$ \\
M8 & 0.417 & 0.122 & -0.294 & $-0.878 * *$ & -0.550 \\
& $(0.215)$ & $(0.063)$ & $(0.796)$ & $(0.398)$ & $(1.961)$ \\
\hline
\end{tabular}

Source: Author's estimation based on the database of BOM and NSO

Note: ** denotes rejection of null hypothesis at the $95 \%$ level of significance. The numbers in parentheses are for standard errors. 

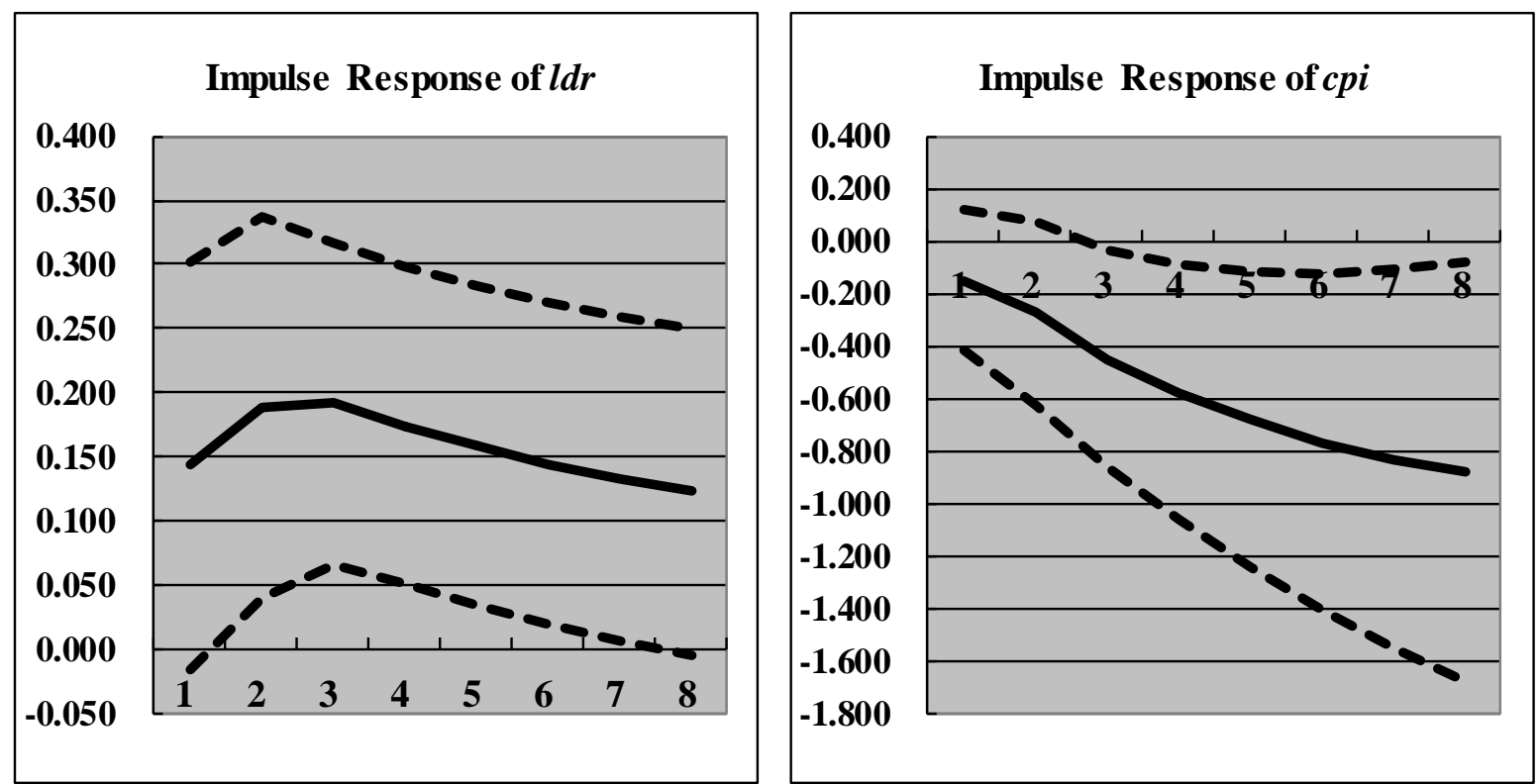

Source: Author's estimation based on the database of BOM and NSO

Figure 4.2. Impulse Responses of $i d r$ and $c p i$ for Post-corridor Period

\section{References}

Bayardavaa. B., Undral. B., \& Altan-ulzii. C. (2015). Monetary Policy Transmission in Mongolia. Bank of Mongolia Research Book, \#11.

Bernanke, B. (1986). Alternative Explanations of the Money-Income Correlation. Carnegie-Rochester Conference Series on Public Policy, 25(1), 49-59. http://dx.doi.org/10.1016/0167-2231(86)90037-0

Bernanke, B., \& Blinder, A. (1992). The federal funds rate and the channels of monetary transmission. American. Economic Review, 82(4), 901-921.

Calvo, G., \& Reinhart, C. (2002). Fear of floating. Quarterly Journal of Economics, 117(2), 379-408. http://dx.doi.org/10.1162/003355302753650274

Christiano, L., Eichenbaum, M., \& Evans, C. (1999). Monetary policy shocks: What have we learned and to what end, In J.B. Taylor and M. Woodford (Eds.), Handbook of macroeconomics, 1A, 65-148. http://dx.doi.org/10.1016/S1574-0048(99)01005-8

Doojav, G., \& Borkhuu, G. (2004). Relation Between Monetary Aggregates and Inflation. Bank of Mongolia Research Book, \#2.

Isakova, A. (2008). Monetary Policy Efficiency in the Economics of Central Asia. Czech Journal of Economics and Finance, 58, 525-553.

Leeper E., Sims C., \& Zao, T. (1998). What does monetary policy do? Brookings Papers on Economic Activity, 2, 1-78. http://dx.doi.org/10.2307/2534619 
Luvsannyam, D. (2004). Lagged Effect of Monetary Policy on Inflation. Bank of Mongolia Research Book, \#3.

Said, S., \& Dickey, D. A. (1984). Testing for unit roots in autoregressive-moving average models of unknown order. Biometrika, 71, 599-607. http://dx.doi.org/10.2307/2336570

Taguchi, H., \& Kato, C. (2011). Assessing the Performance of Inflation Targeting in East Asian economies. Asian-Pacific Economic Literature, 25(1), 93-102. http://dx.doi.org/10.1111/j.1467-8411.2011.01277.x

\section{Notes}

Note 1. The description on this section is based on Bayardavaa et al. (2005) and the BOM website: https://www.mongolbank.mn/eng/listmonetarypolicy.aspx?id=01.

Note 2. The transmission mechanism is described in the BOM website: https://www.mongolbank.mn/eng/listmonetarypolicy.aspx?id=0105

\section{Copyright Disclaimer}

Copyright for this article is retained by the author(s), with first publication rights granted to the journal.

This is an open-access article distributed under the terms and conditions of the Creative Commons Attribution license (http://creativecommons.org/licenses/by/3.0/). 